\title{
Variation in Laboratory Reports: Causes other than Laboratory Error
}

\author{
Santosh Pradhan, ${ }^{1}$ Keyoor Gautam, ${ }^{2}$ Vivek Pant ${ }^{1}$ \\ 'Department of Biochemistry, Samyak Diagnostic Pvt. Ltd, Lalitpur, Nepal, ${ }^{2}$ Department of Pathology, Samyak \\ Diagnostic Pvt. Ltd, Lalitpur, Nepal.
}

\begin{abstract}
When a sample of an individual is measured at different times at the same or different clinical laboratory, the results are always different, even the state of health of an individual is the same. This disparity in the results from clinical laboratories might confuse diagnosing, treating, and monitoring disease. Patients and healthcare professionals usually interpret these differences as laboratory errors. However, this might not always be the case, because laboratory test results are highly variable and are neither consistent nor comparable due to several reasons other than laboratory error, namely preanalytical variation, biological variation, and analytical variation.
\end{abstract}

Keywords: diagnosis; laboratory; report.

\section{INTRODUCTION}

The ultimate goal of the clinical laboratory is to provide accurate and actionable laboratory results that help healthcare professionals to make appropriate diagnostic or therapeutic decisions, hence improving patient outcomes. However, this has always been a herculean task for clinical laboratories. The challenge gets bigger when the question comes about the release of uniform results. The trend in cross-checking and seeking the second opinion in laboratory results is increasing the dilemma rather than enforcing the results, as most of the time the reports released by two laboratories for the same individual (reproducibility) is different and even the reports released by the same laboratory (repeatability) shows variations. ${ }^{1}$ Shortterm (within-day to two weeks) repeatability and short-term reproducibility are more of a concern than long terms (three to six months). This disparity in the results from clinical laboratories has always been an issue and might cause confusion to diagnose, treat and monitor disease.

\section{DISCUSSION}

Patient and healthcare professionals presume that clinical laboratory results of samples from the same individual at the same day or close timeframe released by the same or different laboratories must be similar or at least comparable otherwise they usually interpret the difference as laboratory error. ${ }^{2}$ Though, this might not always be the case, because laboratory test results are highly variable and are neither consistent nor comparable, as a virtue of a number of reasons other than laboratory error. ${ }^{3}$

Variation in laboratory results is possible at any stage of the total testing process which includes the pre-preanalytical phase, pre-analytical phase, analytical phase, post-analytical phase, and post-post-analytical phase. ${ }^{4}$ All laboratories are prone to errors and mistakes at the aforementioned phases. Even the laboratory overcomes all these errors and mistakes, variations in results still exist. And these variations in laboratory results can be summed up as pre-analytical variation, biological variation, and analytical variation. ${ }^{5}$

\section{PRE-ANALYTICAL VARIATION}

Even after the standardization of all potential sources of laboratory error, including specimen collection, transportation, preparation, and storage in the preanalytical phase, considerable variability in the test results does exist. Patient preparation is the commonest pre-analytical factor for this variation. Diet, physical activity, and timing of sampling are major among them that can all have a pre-analytical influence on laboratory results. ${ }^{6}$

Correspondence: $\operatorname{Dr}$ Santosh Pradhan, Department of Biochemistry, Samyak Diagnostic Pvt. Ltd., Lalitpur, Nepal. Email: drsantosh.samyak@gmail.com, Phone: +977-9841439643. 
Ingestion of certain food (Caffeine, alcohol, nicotine, fruits) before the laboratory test has a huge impact on various analytes. Some food shows a short-lasting effect whereas others have a long-term effect. Variation in laboratory results is likely if the test is performed with and without taking such food, especially those with short-lasting effects, at different instances. ${ }^{7}$

Moderate to strenuous exercise has direct effects on the concentration of analytes like aspartate aminotransferase, lactate dehydrogenase, creatinine kinase, and aldolase due to skeletal muscle release. Intense exercise is also linked with altered thyroid function. There are several other analytes that alter with mild to extreme exercise. It has also been proved that concentrations of various analytes show cyclic variation during the course of the day. Serum iron levels may change from $30 \%$ to $50 \%$ within a day. Similarly, growth hormone, testosterone levels peak in the morning whereas evening levels are substantially low. ${ }^{7,8}$

Laboratory professionals routinely identify preanalytical errors and take corrective measures. However, some pre-analytical errors including patient preparation are not under the direct control of the clinical laboratory hence could not be detected at the laboratory end, which might therefore cause a significant impact on test results. ${ }^{9}$

\section{BIOLOGICAL VARIATION}

Every individual has their own homeostatic setting point for every analyte measured. Biological variation is the physiological fluctuation of analyte concentrations around this homeostatic set point. This variation can be of three types, namely; variation over the life (growth, age, menopause), a cyclical variation that can be daily, monthly or seasonal, and random variation. Random variation can be within-subject or intraindividual and between-subject or inter-individual. Within-subject biological variation is defined as the physiological random fluctuation for each individual. And this variation is responsible for the difference in concentration of analytes in each measurement. ${ }^{10}$

\section{ANALYTICAL VARIATION}

Analytical variation occurs due to differences in testing methods and equipment, which results in different analyte values each time they are measured. There can be variations even in the same sample run by the same instrument at close time intervals as all analytical techniques have inherent random variation termed as the analytical imprecision. ${ }^{11}$

Nonetheless, as these variations (within-subject biological variation and analytical variation) are inevitable, how much variation due to these factors is acceptable must be advocated. Reference Change Values (RCV) is one of the objective tools for the assessment of the significance of differences in serial results from an individual. ${ }^{12} \mathrm{RCV}$ provides the critical difference between two results that must be exceeded for a significant change to occur and calculated as,

$\mathrm{RCV}=2^{1 / 2} \times \mathrm{Z} \times\left(\mathrm{CV}_{\mathrm{A}}{ }^{2}+\mathrm{CV}_{1}{ }^{2}\right)^{1 / 2}$, where $\mathrm{Z}$ is the number of standard deviations appropriate to the probability, (Commonly used $Z$ values are 1.96 and 2.56), $\mathrm{CV}_{\mathrm{A}}$ is analytical variation and $\mathrm{CV}_{1}$ is biological variation. ${ }^{13,14}$

As all laboratories have their analytical imprecision $\left(\mathrm{CV}_{\mathrm{A}}\right)$ and database of within-subject biological variation $\left(\mathrm{CV}_{1}\right)$ are available for a large number of analytes (www.westgard.cpm/biodatabase1. htm), calculation of RCV is straightforward. ${ }^{15,16}$ If the difference of two results is less than the calculated $\mathrm{RCV}$ for the particular analyte then the variation is not much of clinical significance and should be interpreted as expected variation due to the inherent random sources i.e. biological and analytical variations. ${ }^{13}$

For instance, if the analytical imprecision $\mathrm{CV}_{\mathrm{A}}$ for serum Glucose is $2.7 \%$ and the biological variation $\mathrm{CV}_{1}$ (taken from the database) is $5.6 \%$ then the $\mathrm{RCV}$ for Glucose, $2^{1 / 2} \times 1.96 \times\left(2.7^{2}+5.6^{2}\right)^{1 / 2}$ is $17 \%$. So the changes in Glucose greater than $17 \%$ are significant and changes less than this is expected due to the inherent random sources of variation. However, to minimize confounding effects, analytical imprecision $\mathrm{CV}_{\mathrm{A}}$ should be less than one-half the within-subject biological variation $\mathrm{CV}_{1}{ }^{1}$ for example $\mathrm{CV}_{\mathrm{A}}(2.7 \%)$ is less than $1 / 2$ of $\mathrm{CV}_{\text {, }}$ i.e. $5.6 \%$.

\section{WAYS FORWARD}

It is rare to get the same results when a sample of the individual is measured at different times, even if the state of health in the individual has not been changed. If such difference in test results from repeated testing is observed, physicians and health care professionals should also be aware of possible factors other than laboratory error. Communication between the physician and laboratory professionals while interpreting such results within the context of pre-analytical, biological, and analytical variations is always imperative.

\section{Conflict of Interest: None.}




\section{REFERENCES}

1. Caudill SP, Boone DJ. Analytical variance and definition of a reference change as a function of calcium concentration. Clin Chem. 1986 Feb;32(2):308-13. [PubMed | Full Text | DOI]

2. Plebani M. Harmonization of Clinical Laboratory Information - Current and Future Strategies. EJIFCC. 2016 Feb 9;27(1):15-22. [PubMed | Full Text]

3. Plebani M. Harmonization in laboratory medicine: Requests, samples, measurements and reports. Crit Rev Clin Lab Sci. 2016;53(3):184-96. [라bMed | Full Text | DOI]

4. Plebani M. Errors in clinical laboratories or errors in laboratory medicine? Clin Chem Lab Med. 2006;44(6):750-9. [PubMed | Full Text | DOI]

5. Sheriff SO, Sheriff DS. Clinical laboratory tests: Right choice of the test for the benefit of the patient. J Health Res Rev. 2014;1(1):10-4. [Full Text | DOI]

6. Irjala KM, Gronroos PE. Preanalytical and analytical factors affecting laboratory results. Ann Med. 1998 Jun;30(3):267-72. [PubMed | Full Text | DOI]

7. Palmer OMP. Effect of age, gender, diet, exercise and ethnicity on laboratory test results. In: Accurate results in the clinical laboratory: a guide to error detection and correction. London; Waltham, MA: Elsevier; 2013.9-17. [Full Text | $\underline{\mathrm{DOI}}]$

8. Narayanan S, Guder WG. Preanalytical Variables and Their Influence on the Quality of Laboratory Results. EJIFCC. 2001 Apr 5;13(1):9-12. [ㅁubMed | Full Text | DOI]

9. Jie Gao. The Preanalytical Errors: a continuous challenge for clinical laboratories [Internet]. Virginia: The American Society of Clinical Laboratory Science; 2021 [cited 2021 Aug 21]. Available from: https://ascls.org/the-preanalytical-errors/. [Full Text]
10. Ricos C, Perich C, Minchinela J, Alvarez V, Simon M, Biosca $\mathrm{C}$, et al. Application of biological variation-a review. Biochem Medica. 2009;19(3): 250-9. [Full Text | DOI]

11. Fraser CG. Biological variation - what's it all about? [Internet]. Denmark: Acucaretesting.org; 2009 Sep [cited 2021 Aug 21]. Available from: https://acutecaretesting.org /en/articles/biological-variation--whats-it-all-about. [ㅍull Text]

12. Fraser CG. Reference change values. Clin Chem Lab Med. 2011 Sep 30;50(5):807-12. [ㄹuMed | Full Text | DOI]

13. Omar F, van der Watt GF, Pillay TS. Reference change values: how useful are they? J Clin Pathol. 2008 Apr;61(4):426-7. [PubMed | Full Text | DOI]

14. Fraser CG, Harris EK. Generation and application of data on biological variation in clinical chemistry. Crit Rev Clin Lab Sci. 1989;27(5):409-37. [ubMed | Full Text | DOI]

15. Fernandez-Grande E, Valera-Rodriguez C, Sáenz-Mateos L, Sastre-Gomez A, Garcia-Chico P, Palomino-Munoz TJ. Impact of reference change value (RCV) based autoverification on turnaround time and physician satisfaction. Biochem Med (Zagreb). 2017 Jun 15;27(2):342-9. [ㄹuMed | Full Text | DOI]

16. Ricos C, Alvarez V, Cava F, Garcia-Lario JV, Hernandez A, Jimenez $C V$, et al. Current databases on biologic variation: pros, cons and progress. Scand J Clin Lab Invest. 1999; 9: 491-500. [․ㅏbMed | Full Text | DOI]

\section{The Author(s) 2022}

This work is licensed under a Creative Commons Attribution 4.0 International License. The images or other third party material in this article are included in the article's Creative Commons license, unless indicated otherwise in the credit line; if the material is not included under the Creative Commons license, users will need to obtain permission from the license holder to reproduce the material. To view a copy of this license, visit http://creativecommons.org/licenses/by/4.0/ 